\title{
The Microscopy Society of America: A Brief Status Report
}

\author{
Ernie Hall, Past-President
}

hallel1254@gmail.com

December 31, 2013, marked the end of my term as president of the Microscopy Society of America. In many ways the year has passed very quickly, but as I review the last twelve months I also feel we were able to accomplish a great deal. As I said at the beginning of the year, it was my assessment that the society was in a very strong position thanks to effective leadership in the past, and this year we have built on that solid foundation through the hard work and dedication of our many volunteer leaders and professional staff.

This year we continued to focus on the society's mission, to promote and advance the techniques and applications of microscopy and microanalysis, or, as I like to say, to serve, connect, and grow microscopy and microscopists. We do that predominantly through our three primary activities: the Microscopy \& Microanalysis meeting; our publications Microscopy and Microanalysis and Microscopy Today; and our programs for outreach, education, and professional development.

This year the Microscopy \& Microanalysis meeting continued to experience near-record levels of paper submissions, attendees, and exhibitors. The credit for the strong scientific content of the meeting was due to our intrepid program chair, Teresa Ruiz, and her excellent Program Committee. Our publications Microscopy and Microanalysis and Microscopy Today continued to grow and lead our field as journal and magazine, communicating both the best research and also innovations in tools and techniques, led by our editors Bob Price $(M a M)$ and Charles Lyman $(M T)$. And our programs in such areas as Education, Certification, Placement, and International Outreach continued to have a significant impact on the professional development of microscopists in the US and elsewhere.

At the beginning of 2013, the MSA Council met and developed three specific goals to focus on this year, in addition to ensuring that the core activities listed above were strongly supported. The first goal was to consider hiring a communications manager, because we realized that communication was core to all that we do and that there were new channels of communication, especially social media, where we definitely needed to improve. In June, after working to define the position, we hired Leah Retting as our half-time communications manager. Leah made an immediate impact, greatly increasing our presence on Facebook, Twitter, and LinkedIn and making communication services available to our committees and local affiliated societies. For example, we now have over 2,000 followers on Facebook and often reach 5,000 or more people each week with news about microscopy and the society.

Our second goal was to connect better with students and early-career researchers. Here we took several actions.
We increased the number of Presidential Scholar Awards for graduate students and postdocs to attend the M\&M meeting to 33. At the meeting, we had many activities for student attendees, including a mixer and a breakfast focus group, where we got ideas on how to better serve this population. We've stayed in touch with the students after the meeting, and Leah has produced a video that describes the student experience at M\&M, which you can view by going to the home page of the MSA website (www.microscopy.org). Students and early-career researchers are the future of our field, so we will continue to try to find ways to connect with these groups.

Finally, our third goal was to strengthen our local affiliated societies (LAS), which work at the grassroots level to connect and grow a large number of microscopists, many of whom are rarely able to attend a national meeting. In this area, we doubled the funding for program and meeting support for the LASs and also made our newly developed communications resources and tools available for their use.

As I look back, I feel proud of the many accomplishments that the society had in 2013. Certainly none of this would have been possible without our talented volunteers and staff. Our staff includes Bob Dzuibian and Ashley Carey at our association management headquarters; Nicole Guy and Doreen Bonnema, our meeting and exhibition managers, respectively; and Aaron Johnson, our senior editor at Cambridge University Press. All of these fine folks are excellent at what they do and are great to work with. I'd also like to acknowledge the Executive Committee of MSA Council: Janet Woodward (past president), Jeanette Killius (president-elect), Ian Anderson (secretary), and JoAn Hudson (treasurer). This group met weekly by phone to guide the business of the society.

As I exit the role of president, I turn over the job to Jeanette Killius. Jeanette has served the society in many roles for many years and is well-prepared to be president. She loves the society and cares deeply about the people in it. I know she will be a very successful president, and I look forward to advising her as past president.

To all of you, members of the society, I give you my thanks for the opportunity and privilege to serve in this way. MSA has had an extremely important role in my professional development, and those of us who serve in leadership are always determined to ensure MSA continues to play that role for others. I hope you will consider becoming more active in the life of the society, perhaps as a member of one of our committees. And my wish for you and MSA is for great success in the new year. 


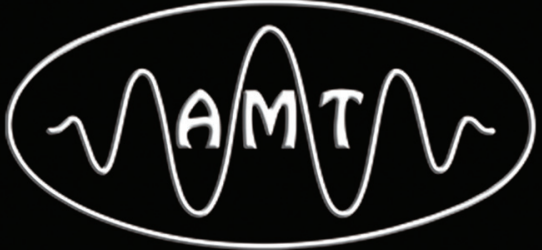

High Definition Digital

TEM Cameras with

1 to 16 Megapixels
- AMT SOLUTIONS

- Life Science Cameras

- Material Science Cameras

- Easy To Use Software

- Reliability and Services

-TEM Integration

- Extensive Support
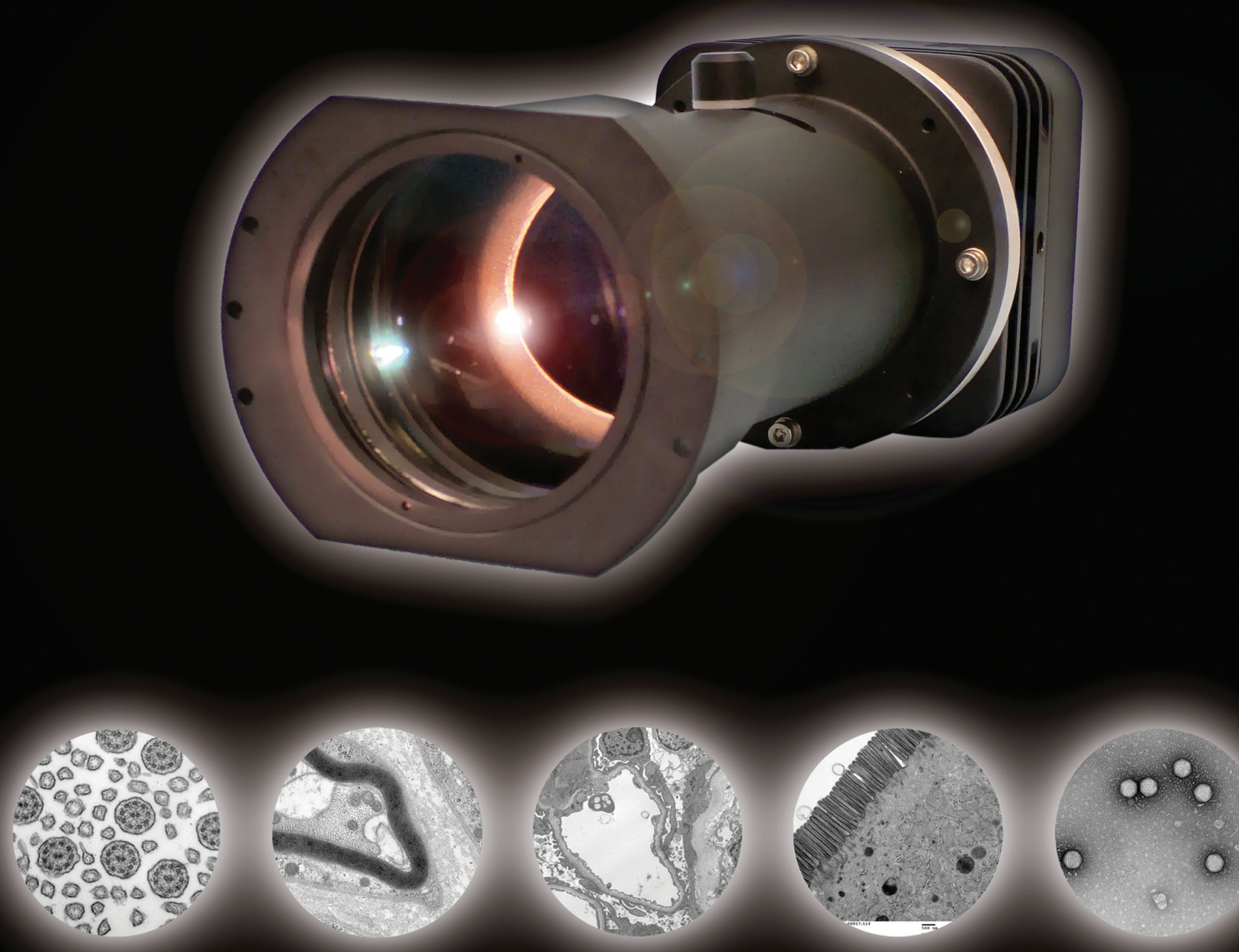